\title{
O MUNICÍPIO DE MARABÁ, PA FRENTE AO ZEE NA AMAZÔNIA LEGAL: AVALIAÇÃO DAS TAXAS DE DESMATAMENTO
}

\author{
Edson Antonio Mengatto Junior ${ }^{(a)}$, Regina Célia de Oliveira ${ }^{(b)}$, João dos Santos Vila da Silva ${ }^{(\mathrm{c})}$ \\ (a) Instituto de Geociências/ UNICAMP, mengattogeo@gmail.com \\ (b) Instituto de Geociências/ UNICAMP, reginacoliveira@ige.unicamp.br \\ (c) Embrapa Informática Agropecuária, joao.vila@embrapa.br
}

\section{Eixo: GEOTECNOLOGIAS E MODELAGEM ESPACIAL EM GEOGRAFIA FÍSICA}

\begin{abstract}
Resumo
A Amazônia Legal possui elevada diversidade de espécies de fauna e flora, sendo constituída por nove Estados brasileiros. Tornou-se alvo de intensa exploração tendo taxas de desmatamento elevadas. O ordenamento territorial, a partir do planejamento ambiental, é instaurado com a criação de leis como os zoneamentos ecológico-econômicos. O município de Marabá ganha destaque negativo devido aos altos índices de desmatamentos associados ao estado do Pará, sendo importante por sua função econômica no estado. O objetivo do trabalho foi avaliar as informações das taxas de desmatamento entre os períodos de 2000 a 2015. Os resultados demonstram que houve crescimento das áreas desmatadas, a uma taxa aproximada de $1 \%$ ao ano. A distribuição espacial dos dados demonstra que o desmatamento acontece de maneira distribuída no município. Os resultados mostram ser necessário a existência de planejamentos ambientais bem elaborados para a mitigação de processos de exploração predatória dos recursos naturais, importantes sobretudo para as populações tradicionais residentes nestas áreas.
\end{abstract}

Palavras chave: zoneamento ecológico-econômico, planejamento, ordenamento territorial, geotecnologias

\section{Introdução}

A Amazônia Legal é uma importante área do território nacional, sobretudo, devido a sua rica biodiversidade de espécies de fauna e flora. É composta por nove estados brasileiros: Acre, Amapá, Amazonas, Mato Grosso, Pará, Rondônia, Roraima, Tocantins e parte do Estado de Maranhão, meridiano de $44^{\circ}$ de longitude Oeste (MMA, 2010).

Segundo MMA (2010),

dotada de inestimável capital natural e riqueza cultural, a Amazônia brasileira tem se tornado centro de interesses estratégicos que movem a política e a economia no mundo atual, visando a utilização dos recursos hídricos, minerais, fundiários, genéticos, energéticos, a produção de biocombustíveis e alimentos e agora, também, a prestação de serviços ambientais (2010, p 19).

$\mathrm{Na}$ tentativa de diminuir a exploração de seus recursos de forma desordenada, o governo federal e os estados componentes desta região elaboraram o Plano Amazônia Sustentável, lançado em 2008 e com intuito de valorização da diversidade sociocultural e ecológica e redução das desigualdades regionais 
OS DESAFIOS DA GEOGRAFIA FÍSICA NA FRONTEIRA DO CONHECIMENTO

Instituto de Geociências - Unicamp

Campinas - SP

28 de Junho à 02 de Julho de 2017

propondo um novo modo de produzir, que seja baseado na ciência e tecnologia de ponta, garantindo a disposição destes recursos naturais para outras gerações (MMA, 2010).

Na Amazônia Legal os principais motivos do descontrole ambiental se dá pelo desmatamento devido ao avanço das fronteiras agrícolas, crescimento industrial, da mineração, pecuária e exploração madeireira que demandam a expansão de estradas que vão aumentando o acesso às florestas (Laurance et al., 2001).

Com o objetivo de organizar o território de maneira adequada, através do ordenamento territorial, estabelecendo leis para seu uso, foram criados o Macrozonemanto da Amazônia Legal (Lei 7.378 de 2010) e o zoneamento ecológico-econômico dos estados inseridos nesta região, como o estado do Pará (leis 7.243 de 2009 e 7.398 de 2010), na tentativa de atender às necessidades sociais e ás exigências ambientais e econômicas desta área. O Zoneamento Ecológico-Econômico (ZEE) é um instrumento de planejamento e organização do território, definido como um instrumento político e técnico de planejamento, cuja finalidade última é otimizar o uso do território e as políticas públicas.

A avaliação da taxa de desmatamento é uma das informações de maior utilização para o gerenciamento da região amazônica, devido a importância da floresta para todo o território nacional e para o funcionamento do planeta. Recentemente, dados derivados do Projeto de Monitoramento do Desmatamento na Amazônia Legal por Satélite (PRODES), produzidos pelo Instituto Nacional de Pesquisas Espaciais (INPE), apontaram que houve aumento na taxa de desmatamento estimada para o ano de 2016 na região. Entre os Estados analisados no PRODES, o estado do Pará ganha destaque negativo devido ao elevado índice de desmatamento encontrado para suas áreas, sendo o Estado com maior índice no ano de 2015? (INPE, 2016).

Inserido na área do ZEE da Zona Leste e Calha Norte e, mais especificamanete dentro deste zoneamento, pertencentes às zonas definidas por lei como usos consolidados/a consolidar, o município de Marabá apresenta taxas alarmantes de desmatamento, já que essas zonas se caracterizam como áreas onde o uso dos rescursos naturais pode garantir, mediante crescente incorporação de progresso técnico, melhor qualidade de vida à população, sendo possível a exploração destas áreas de forma mais intensa. Assim, tornam-se necessários planejamentos visando a mitigação dos efeitos dosdesmatamentos e a preocupação com as populações tradicionais dependentes de seus recursos naturais.

Além disso, Marabá é o quarto município mais populoso, o que evidencia sua importância perante o Estado do Pará (Pará, 2010, p 50). O modelo econômico de exploração dominante nesta região inclui a exploração de minérios na região da Serra dos Carajás e a criação extensiva de bovinos nas áreas pastagens do município, além da exploração do turismo na região. 
O objetivo deste trabalho é avaliar a taxa de desmatamento entre os anos de 2000 a 2015 disponibilizado pelos PRODES para o município de Marabá, PA já que este é um importante indicador para o ZEE do Estado e do governo federal.

\section{Caracterização da área de estudos}

De acordo com IBGE cidades (2017), inserido no Estado do Pará, o município de Marabá possui área da unidade territorial de $15.128,058 \mathrm{~km}^{2}$, população estimada em 2016 de 266.932 pessoas, o que significa uma densidade populacional 15,45 (habitantes/ $\mathrm{km}^{2}$ ). Sua emancipação como município se deu em 1913, desmembrando-se do municipio de Baião.

Apresenta clima do tipo Tropical semiumido (Aw) com temperatura média anual de 26 e pluviometria média de $2.200 \mathrm{~mm}$ anuais. Está localizado na região sudeste do Pará, próxima a Serra dos Carajás. A serra dos Carajás, alias, foi fator preponderante para seu desenvolvimento rápido. O município é o quarto mais populoso do Estado do Pará. A localização do município de Marabá (figura 1), permite verificar que ele está totalmente inserido na Zona Leste e Calha Norte.

Marabá possui relevância econômica frente ao Estado do Pará, devido a seu elevado potencial turístico, com desenvolvimento do turismo a partir de bases sustentáveis. Seu potencial produtivo, com regulação da mineração e apoio à diversificação de cadeias produtivas é acentuado devido à presença do entrocamento de importantes rodovias federais, como as BR-155, BR-230 e BR-153, além das rodovias regionais, como a PA-150, e da ferrovia Estrada de Ferro Carajás, que permite o escoamento da produção de ferro gusa derivado da exploração da Serra dos Carajás e também de fluxos de soja cultivados no nordeste de Mato Grosso, para o porto de Itaqui no Maranhão (MMA, 2010), devido a confluência dos rios Itacaiúnas e Tocantins. O município concentra a maioria da população da região de Carajás (Pará, 2010, p 63), acentuando seu papel na polarização do espaço regional, através da prestação de serviços, como hospitais, educação, comércio, entre outros.

Destaca-se também devido a sua atividade pecuária, sendo uma das áreas de maior produção de bovinos (Pará, 2010, p 149), sendo, portanto, uma área de presença intensa de pastagem, através do desmatamento de extensas áreas para a criação bovina. 
XVII Simpósio Brasileiro de Geografia Física Aplicada

I Congresso Nacional de Geografia Física

\section{OS DESAFIOS DA GEOGRAFIA FÍSICA NA FRONTEIRA DO CONHECIMENTO \\ Instituto de Geociências - Unicamp Campinas - SP \\ 28 de Junho à 02 de Julho de 2017}
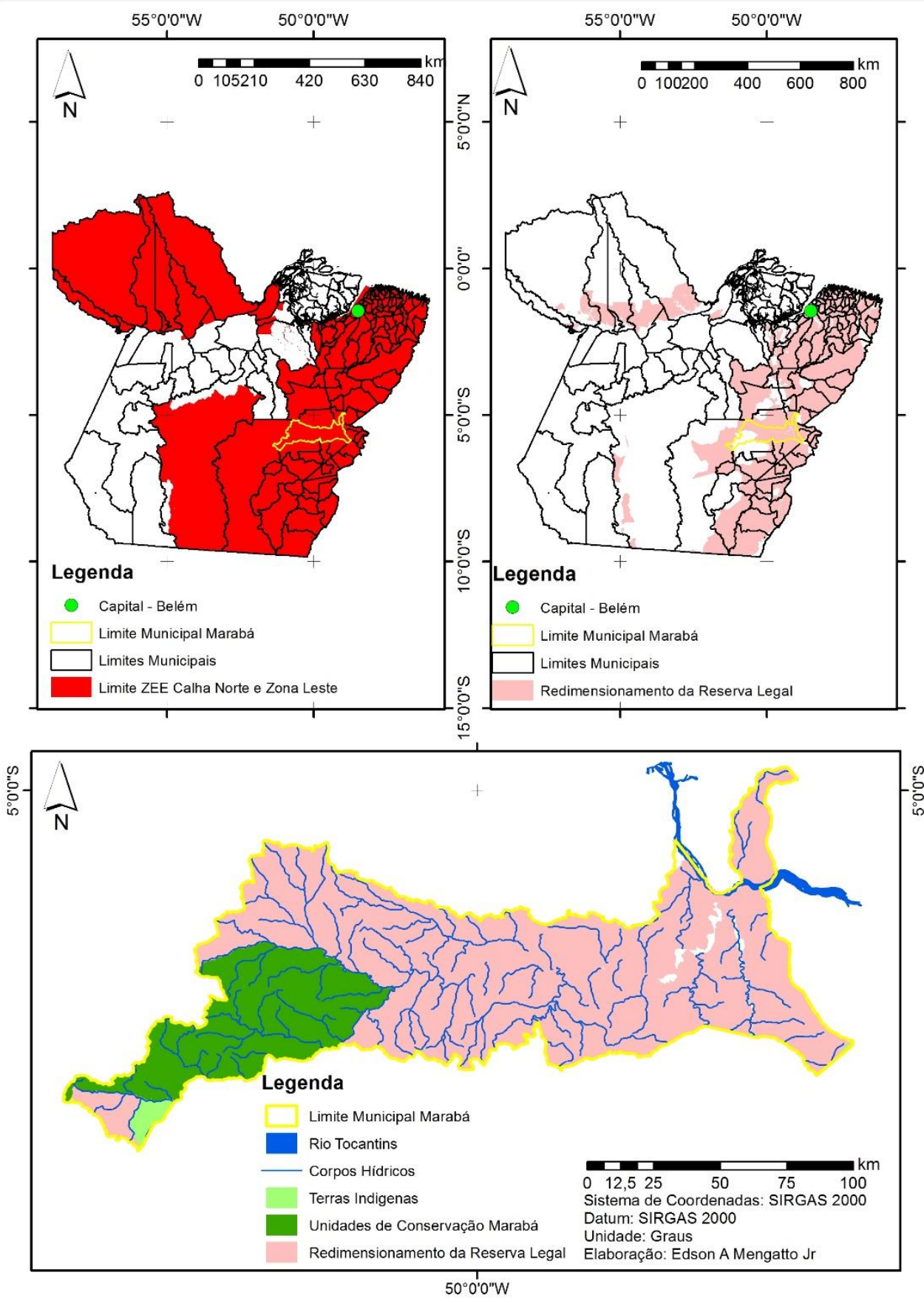

Figura 1. Localização do município de Marabá, PA

\section{Material e métodos}

O fluxograma a seguir apresenta o método de trabalho utilizado para a produção das informações utilizadas como resultados. 


\section{OS DESAFIOS DA GEOGRAFIA FÍSICA NA FRONTEIRA DO CONHECIMENTO Instituto de Geociências - Unicamp \\ Campinas - SP \\ 28 de Junho à 02 de Julho de 2017}

Assim, a etapa 1 envolveu a coleta de dados do PRODES ${ }^{1}$, derivados do site do INPE e avaliados entre os anos de 2000 a 2015. Estes dados deram origem a tabela e aos gráficos: (1) de área desmatada e (2) de distribuição do incremento do desmatamento e distribuição da extensão do desmatamento, entre os anos de 2001 a 2015.

Já na etapa 2, foram obtidos dados do IBGE (limites municipais e limite estadual), além dos limites do Zoneamento Ecológico-Econômico da Zona Leste e Calha Norte e das Áreas Especiais, obtidos do Portal SIAGEO². Assim, foi possível a construção do mapa de Localização apresentado.

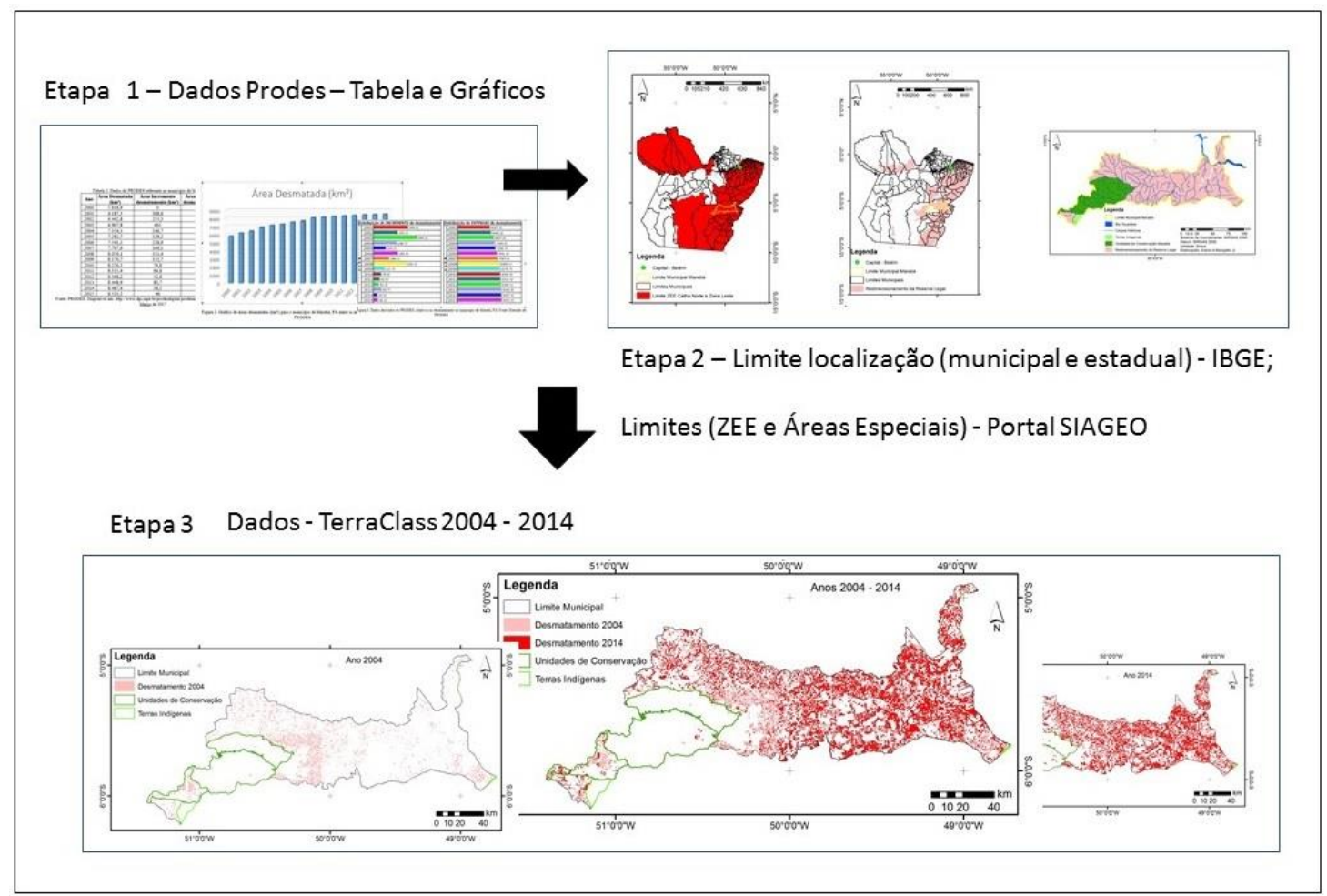

Fluxograma 1. Métodos utilizados na pesquisa

Por fim, a etapa 3 se deu na construção dos mapas de desflorestamento, para os anos de $2004-2014$. Os dados foram obtidos do Projeto TerraClass, que é resultado de parceria entre INPE/CRA (Centro Regional da Amazônia) e Embrapa Amazônia Oriental, além da Embrapa Informática Agropecuária, e tem como objetivo produzir mapas sistêmicos de uso e cobertura das terras desflorestadas da Amazônia Legal Brasileira (Almeida et al, 2016).

\footnotetext{
$1 \quad$ http://www.obt.inpe.br/prodes/index.php

2 http://www.amazonia.cnptia.embrapa.br/
} 
XVII Simpósio Brasileiro

de Geografia Fisica Aplicada

I Congresso Nacional

de Geografia Física

\section{OS DESAFIOS DA GEOGRAFIA FÍSICA NA FRONTEIRA DO CONHECIMENTO \\ Instituto de Geociências - Unicamp \\ Campinas - SP \\ 28 de Junho à 02 de Julho de 2017}

\section{Resultados e Discussão}

O zoneamento da Zona Leste e Calha Norte, foi oficialmente homologado a partir da lei numero 7.398, de Abril de 2010. Assim, a avaliação dos dados de desmatamento entre o período de 2000 a 2015, é importante indicador de qualidade do ordenamento territorial e planejamento ambiental, pois compreende período de 10 anos antes da homologação da lei (2000 a 2010) e 5 anos posteriores a aprovação de seu zoneamento (2010 a 2015), permitindo avaliar se o ZEE tem contribuido para a diminuição ou não das áreas desmatadas, considerando a importância ambiental destas áreas em âmbitos regionais e até nacional.

A tabela 1 apresenta as informações referentes ao desmatamento, apresentando para tanto, o ano, a área mapeada desmatada $\left(\mathrm{km}^{2}\right)$, a área de incremento do desmatamento $\left(\mathrm{km}^{2}\right)$ e a porcentagem de representação desta área de incremento (\%).

Tabela 1. Dados do PRODES referente ao município de Marabá, PA

\begin{tabular}{|c|c|c|c|}
\hline Ano & $\begin{array}{c}\text { Área Desmatada } \\
\left(\mathbf{k m}^{2}\right)\end{array}$ & $\begin{array}{c}\text { Área Incremento } \\
\text { desmatamento }\left(\mathbf{k m}^{2}\right)\end{array}$ & $\begin{array}{c}\text { Área Incremento } \\
\text { desmatamento }(\%)\end{array}$ \\
\hline 2000 & $\mathbf{5 . 8 1 8 , 9}$ & $\mathbf{0}$ & $\mathbf{0}$ \\
\hline 2001 & $\mathbf{6 . 1 8 7 , 5}$ & $\mathbf{3 6 8 , 6}$ & $\mathbf{2 , 4 3}$ \\
\hline 2002 & $\mathbf{6 . 4 4 2 , 8}$ & $\mathbf{2 5 5 , 3}$ & $\mathbf{1 , 6 8}$ \\
\hline 2003 & $\mathbf{6 . 9 0 7 , 8}$ & $\mathbf{4 6 5}$ & $\mathbf{3 , 0 7}$ \\
\hline 2004 & $\mathbf{7 . 1 5 4 , 5}$ & $\mathbf{2 4 6 , 7}$ & $\mathbf{1 , 6 3}$ \\
\hline $\mathbf{2 0 0 5}$ & $\mathbf{7 . 2 8 2 , 7}$ & $\mathbf{1 2 8 , 2}$ & $\mathbf{0 , 8 5}$ \\
\hline 2006 & $\mathbf{7 . 5 4 1 , 5}$ & $\mathbf{2 5 8 , 9}$ & $\mathbf{1 , 7 1}$ \\
\hline $\mathbf{2 0 0 7}$ & $\mathbf{7 . 7 0 7 , 6}$ & $\mathbf{1 6 6 , 1}$ & $\mathbf{1 , 1}$ \\
\hline 2008 & $\mathbf{8 . 0 5 9 , 1}$ & $\mathbf{3 5 1 , 4}$ & $\mathbf{2 , 3 2}$ \\
\hline 2009 & $\mathbf{8 . 1 7 0 , 7}$ & $\mathbf{1 1 1 , 7}$ & $\mathbf{0 , 7 4}$ \\
\hline 2010 & $\mathbf{8 . 2 5 0 , 5}$ & $\mathbf{7 9 , 8}$ & $\mathbf{0 , 5 3}$ \\
\hline $\mathbf{2 0 1 1}$ & $\mathbf{8 . 3 1 5 , 4}$ & $\mathbf{6 4 , 8}$ & $\mathbf{0 , 4 3}$ \\
\hline 2012 & $\mathbf{8 . 3 6 8 , 2}$ & $\mathbf{5 2 , 8}$ & $\mathbf{0 , 3 5}$ \\
\hline 2013 & $\mathbf{8 . 4 4 8 , 9}$ & $\mathbf{8 0 , 7}$ & $\mathbf{0 , 5 3}$ \\
\hline 2014 & $\mathbf{8 . 4 8 7 , 4}$ & $\mathbf{3 8 , 5}$ & $\mathbf{0 , 2 5}$ \\
\hline 2015 & $\mathbf{8 . 5 3 3 , 5}$ & $\mathbf{4 6}$ & $\mathbf{0 , 3}$ \\
\hline
\end{tabular}

Fonte: PRODES. Disponível em: http://www.dpi.inpe.br/prodesdigital/prodesmunicipal.php. Acesso em 10 de Março de 2017

$\mathrm{Na}$ avaliação dos dados do PRODES para o município de Marabá, PA é possível afirmar que as áreas mapeadas como desmatadas apresentaram crescimento ao longo dos 15 anos avaliados (2000 a 2015), tendo evoluído de uma área de $5.818,9 \mathrm{~km}^{2}$ para uma área aproximada de $8.533,5 \mathrm{~km}^{2}$, o que representou quase $46,6 \%$ de áreas totais mapeadas para o desmatamento. No entanto, é possível notar também que a taxa de incremento de áreas desmatadas sofre queda constante de suas áreas, tendo apresentado somente $0,3 \%$ de evolução entre o ano de 2014 para o ano de 2015 , período avaliado pois os dados do ano de 2016 para os municípios ainda não foram disponibilizados no PRODES. 


\section{OS DESAFIOS DA GEOGRAFIA FÍSICA NA FRONTEIRA DO CONHECIMENTO \\ Instituto de Geociências - Unicamp \\ Campinas - SP \\ 28 de Junho à 02 de Julho de 2017}

É possível notar ainda que o maior crescimento das áreas desmatadas se dá em relação ao período de 2000 a 2008, já que a partir do ano de 2009 o crescimento é praticamente estabilizado nestas áreas analisadas. Esta estabilização possivelmente esteja condicionada à criação do ZEE, já que um dos principais objetivos do zoneamento é justamente melhorar a qualidade do planejamento ambiental proposto, através de ordenamentos territorias mais adequados para as áreas inseridas neste ZEE, sendo importante instrumento técnico utilizado para mitigar processos de exploração de seus recursos naturais.

A partir destas informações, foi possível a organização da figura 2, em que são apresentadas as áreas desmatadas, onde é possível verificar a evolução de desmatamento mapeados para o período avaliado (2000 a 2015), sendo possível notar o crescimento das áreas desmatadas ao longo dos anos avaliados.

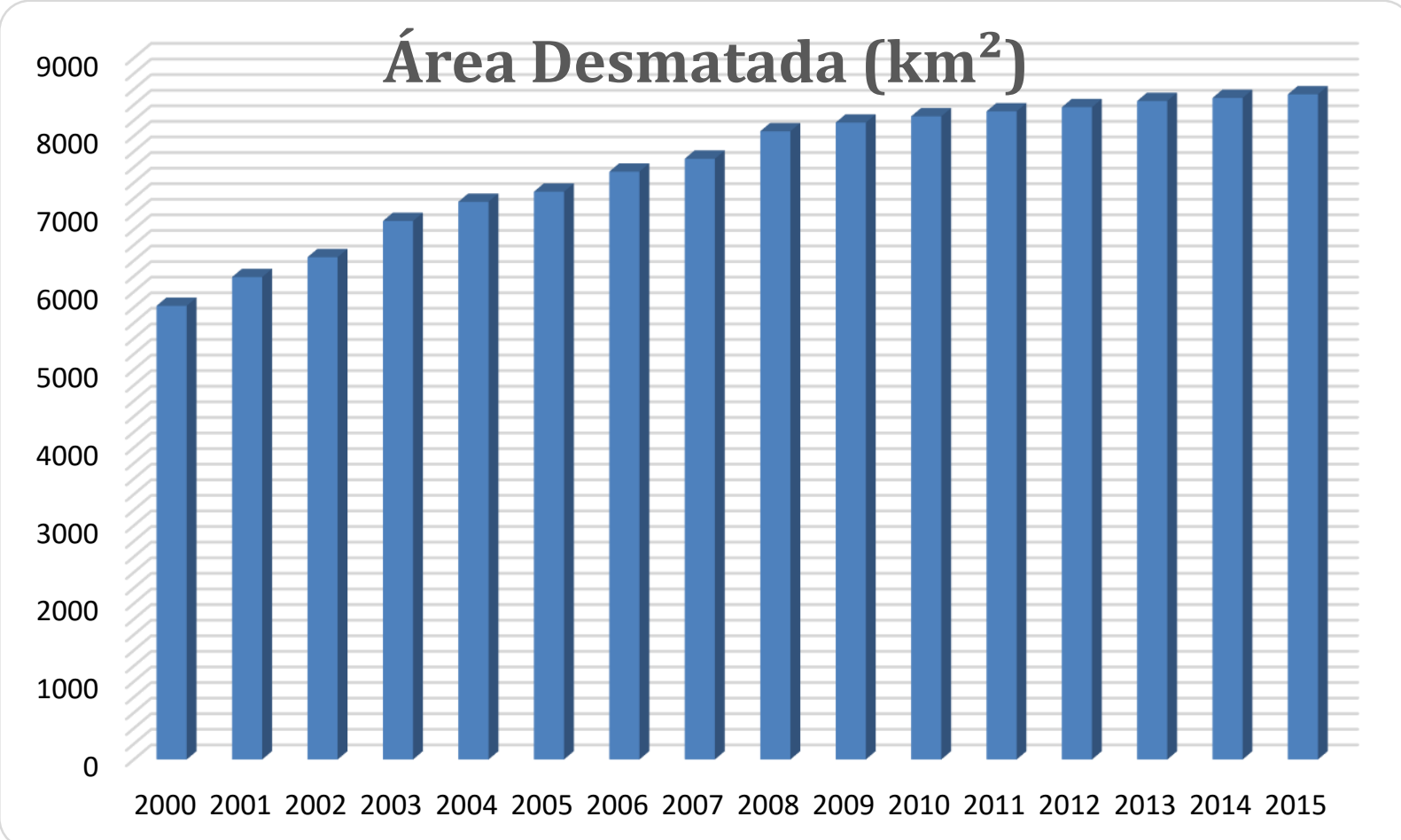

Figura 2. Gráfico de áreas desmatadas $\left(\mathrm{km}^{2}\right)$ para o município de Marabá, PA entre os anos de 2000 a 2015. Fonte: PRODES

A estabilização destas taxas de desmatamento fica evidente a partir da análise visual do gráfico acima, em que é possível verificar que o período compreendido entre os anos de 2008 a 2015, o gráfíco se torna mais constante, com menor variação da curva de áreas desmatadas.

Com estas avaliações visualizadas na figura 2 e os dados disponibilizados na tabela 1 , foi possível a elaboração dos gráficos de distribuição do Incremento do desmatamento e a distribuição da extensão do desmatamento para o município de Marabá, que estão disponibilizados na figura 3. 
XVII Simpósio Brasileiro de Geografia Fisica Aplicada

I Congresso Nacional de Geografia Física

\begin{tabular}{|c|c|c|}
\hline \multicolumn{3}{|c|}{ Distribuição do INCREMENTO do desmatamento } \\
\hline \multicolumn{3}{|c|}{$2001 \quad(368.6)$} \\
\hline & 2002 & $(255.3)$ \\
\hline & 2003 & $(465.0)$ \\
\hline & 2004 & $(246.7)$ \\
\hline & 2005 & $a_{(128.2)}$ \\
\hline & 2006 & $(258.9)$ \\
\hline A & 2007 & (166.1) \\
\hline n & 2008 & $(351.4)$ \\
\hline $\mathbf{s}$ & 2009 & (111.7) \\
\hline & 2010 & $(79.8)$ \\
\hline & 2011 & (64.8) \\
\hline & 2012 & $(52.8)$ \\
\hline & 2013 & $(80.7)$ \\
\hline & 2014 & $(38.5)$ \\
\hline & 2015 & $(46.0)$ \\
\hline
\end{tabular}

OS DESAFIOS DA GEOGRAFIA FÍSICA NA FRONTEIRA DO CONHECIMENTO

Instituto de Geociências - Unicamp

Campinas - SP

28 de Junho à 02 de Julho de 2017

Figura 3. Dados derivados do PRODES, relativos ao desmatamento no município de Marabá, PA. Fonte: Extraído de PRODES

Como citado acima, é possível notar, portanto, que esse crescimento (a partir da avaliação do incremento de áreas desmatadas), ocorre de forma mais acentuada no perído de 2000 a 2008, tendo menor crescimento para os anos de 2009 a 2015, sendo que o menor incremento encontrado foi no ano de 2014 , com $38,5 \%$ de novas áreas mapeadas como desmatadas.

Os dados do projeto TerraClass apresentam o crescimento aproximado das classes denominadas desflorestadas e permitiram a construção da distribuição espacial da classe desflorestada, considerando o período temporal de 2004-2014, aproximando-se também do período temporal derivado do PRODES.

Com as informações espaciais do TerraClass, foi possível a construção do mapa de desmatamento (áreas desflorestadas e vegetação secundária), para o ano de 2004 e 2014, além do mapa composto das duas áreas, que permite melhor compreensão da dinâmica de aumento dessas áreas. Assim, a figura 4 apresenta a distribuição espacial das áreas desmatadas, entre os anos de 2004 a 2014.

A análise da figura demonstra que a evolução das áreas desmatadas ocorre de forma bem distribuída, excetuando-se a região sudoeste do município, já que nestas áreas têm-se a existência de Unidades de Conservação federais (Flona Itacaiúnas, Flona Tapurapé-Aquiri e Rebio Tapirapé) e Terras Indígenas, que são áreas onde o uso é restrito e cujas leis, são próprias para a proteção integral de suas áreas, de acordo como definido nos zoneamentos ecológicos-econômicos homologados para estas áreas. 


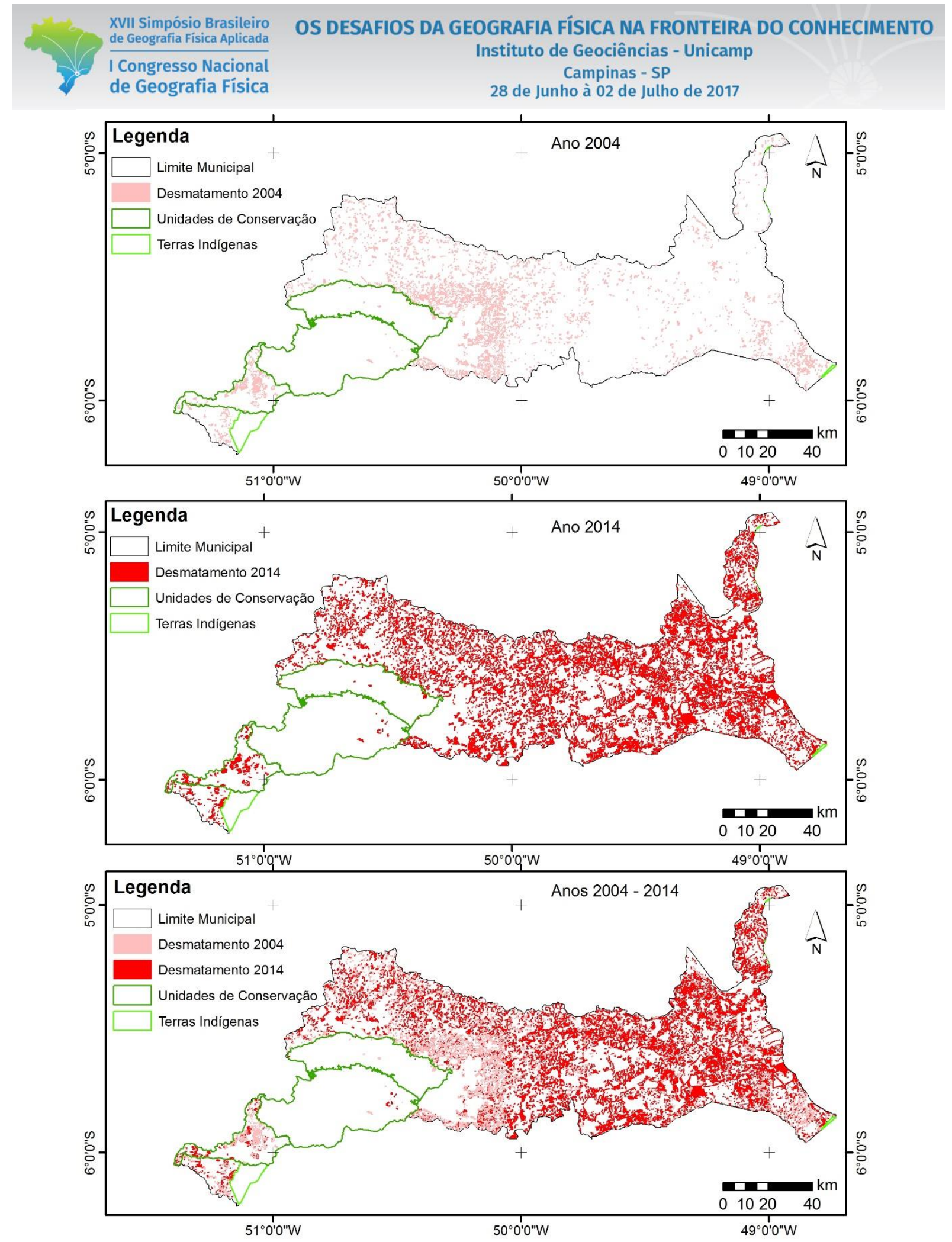

Figura 4. Distribuição espacial do desflorestamento das áreas, entre os anos de 2004 - 2014

Segundo os dados derivados do PRODES para o ano de 2004 (ano de ínicio de divulgação das informações do TerraClass), a área desmatada foi de aproximadamente $7.150 \mathrm{~km}^{2}$, que representa $45 \%$ da área total do município. Ja para o ano de 2014 (último ano disponível dos dados do TerraClass), a área mapeada como desmatamento foi de $8.480 \mathrm{~km}^{2}$, representando aproximadamente $56 \%$ da área total do municipio. Assim, conclui-se que o aumento das áreas desmatadas no período avaliado foi de 
OS DESAFIOS DA GEOGRAFIA FÍSICA NA FRONTEIRA DO CONHECIMENTO

Instituto de Geociências - Unicamp

Campinas - SP

28 de Junho à 02 de Julho de 2017

aproximadamente $1.300 \mathrm{~km}^{2}$, ou $11 \%$ da área total do municipio. Assim, o crescimento dentro do período temporal avaliado foi de $11 \%$ em aproximadamente 10 anos, sendo portanto, um crescimento de pouco mais de $1 \%$ ao ano (ou pouco mais de $100 \mathrm{~km}^{2}$ por ano).

Considerando-se o novo código florestal vigente (Lei 12.651/2012), todo imóvel localizado em área da Amazônia Legal deve manter uma área com cobertura de vegetação nativa, a título de Reserva legal, com a função de assegurar o uso econômico de modo sustentável dos recursos naturais, auxiliar a conservação e reabilitação dos processos ecológicos e promover a conservação da biodiversidade, bem como proteção de fauna silvestre e flora nativas. Além disso, o poder público estadual poderá reduzir a Reserva Legal, anteriormente de $80 \%$ para 50\%, para fins de regularização em alguns casos.

Tendo em vista o momento atual de aumento das taxas de desmatamento na Amazônia, do Estado do Pará e mais especificamente no muncípio do Marabá, foco deste trabalho, algumas propostas para a contenção dessas áreas devem ser elaboradas, buscando melhores condições para o desenvolvimento econômico da região, mas considerando também as condições sociais e ambientais da região. Com isso, uma das formas de contenção podem ser as propostas de criação de novas Unidades de Conservação ou expansão das áreas das Unidades já existentes, através do planejamento ambiental, em que as decisões sobre o futuro dependem da compreensão das mudanças da paisagem resultantes das pressões humanas através do tempo e que considerem as diversas escalas no espaço a ser planejado.

\section{Conclusões}

O uso de informações de desmatamento derivadas de projetos como o PRODES e o TerraClass como indicador, permitem uma avaliação da efetividade dos zoneamentos criados para estas áreas, pois os zoneamentos são criados tendo em vista a mitigação de processos de exploração inadequada dos recursos naturais, avaliando-se também as condições físicas e sociais da área zoneada. Isso porque o aumento do desmatamento nestas áreas podem se tornar problemáticas para a dinâmica natural ambiental, importante reduto de espécies de fauna e flora.

A gestão adequada das áreas dispostas na Amazônia legal devem ser criteriosamente planejadas, evitando a perda de recursos naturais e garantindo seu uso para gerações futuras, com mudanças de processos produtivos e paradigmas que dominam a região de forma extrativista desde sua colonização. Assim, deve se atingir o conceito de desenvolvimento sustentável desta região, considerando as vulnerabilidades de suas áreas e as condições de vidas das populações tradicionais.

O município de Marabá ao atingir 46\% de áreas desmatadas, se aproxima do máximo permitido para estas áreas, que é de 50\%, excetuando-se, como mostrado na figura 4, as áreas pertecentes a proteção integral, como as terras indígenas e Unidades de Conservação. 
O uso de ferramentas técnicas como as geotecnologias podem auxiliar na elaboração de propostas de gestão dessas áreas, de forma mais ágil, menos custosa financeiramente e organizada, a partir da utilização de banco de dados para a produção e análise das informações.

\section{Agradecimentos}

Agradecemos a Coordenação de Aperfeiçoamento de Pessoal de Nível Superior (CAPES) pela concessão da bolsa de estudos do programa de doutorado do Instituto de Geociências da UNICAMP.

\section{Bibliografia}

ALENCAR, A.; NEPSTAD, N; MCGRATH, D; MOUTINHO, P; PACHECO, P; DIAZ, M. D. C. V e FILHO, B. S. Desmatamento na Amazônia: indo além da emergência crônica. Manaus, Instituto de Pesquisa Ambiental da Amazônia (Ipam), 2004, 89 p.

ALMEIDA, C.A.; COUTINHO, A.C.; ESQUERDO, J.C.D.M.; ADAMI, M.; VENTURIERI, A.; DINIZ, C.G.; DESSAY, N.; DURIEUX, L.; GOMES, A.R High spatial resolution land use and land cover mapping of the Brazilian Legal Amazon in 2008 using Landsat-5/TM and MODIS data. In: Acta Amazonica, Vol 46 (3) 2016 : 291-302.

BRASIL. Lei 1.806. Dispõe sobre o plano de valorização Econômica da Amazônia, cria a superintendência da sua execução e dá outras providências. Disponível em: http://www2.camara.leg.br/legin/fed/lei/1950-1959/lei1806-6-janeiro-1953-367342-publicacaooriginal-1-pl.html. Acesso em 10 de janeiro de 2017.

BRASIL. Lei 5.173. Dispõe sobre o Plano de Valorização Econômica da Amazônia; extingue a Superintendência do Plano de Valorização Econômica da Amazônia (SPVEA), cria a Superintendência do Desenvolvimento da Amazônia (SUDAM), e dá outras providências. Disponível em:<

http://www.planalto.gov.br/ccivil_03/leis/L5173.htm>. Acesso em 13 de janeiro de 2017.

BRASIL. Lei 12.651. Dispõe sobre a proteção da vegetação nativa; altera as Leis nos 6.938, de 31 de agosto de 1981, 9.393, de 19 de dezembro de 1996, e 11.428, de 22 de dezembro de 2006; revoga as Leis nos 4.771, de 15 de setembro de 1965, e 7.754, de 14 de abril de 1989, e a Medida Provisória no 2.166-67, de 24 de agosto de 2001; e dá outras providências. Disponível em < http://www.planalto.gov.br/ccivil_03/_ato20112014/2012/lei/112651.htm>. Acesso em 05 de Março de 2017.

IBGE. Instituto Brasileiro de Geografia e Estatísticas. Áreas Especiais. Cadastro de Municípios localizados na Amazônia Legal. Disponível em:< http://www.ibge.gov.br/home/geociencias/geografia/amazonialegal.shtm?c=2>. Acesso em 25 de janeiro de 2017. 
IBGE. Instituto Brasileiro de Geografia e Estatísticas. Cidades. Disponível em: < http://cidades.ibge.gov.br/xtras/perfil.php?lang=\&codmun=150420\&search=\|infogr\%E1 ficos:informa\%E7\%F5es-completas>. Acesso em 17 de janeiro de 2017.

INPE. Instituto Nacional de Pesquisas Espaciais. PRODES estima $7.989 \mathbf{~ k m}^{\mathbf{2}}$ de desmatamento por corte raso na Amazônia em 2016. Disponível em:<http://www.inpe.br/noticias/noticia.php?Cod_Noticia=4344>. Acesso em 27 de dezembro de 2016.

MMA. Ministério do Meio Ambiente. MACROZEE da Amazônia Legal: estratégias de transição para a sustentabilidade. Brasília: Ministério do Meio Ambiente, 2010. 151 p. Inclui 9 mapas.

MENGATTO JUNIOR. E. A. M.; SILVA. J. dos S. V.; DIAS, D. A.; SANTOS, J. L. dos; V.; FIGUEIREDO, V. A. Informações Geoespaciais da Amazônia Legal na Internet. In: Simpósio de Estudos e pesquisas em Ciências Ambientais na Amazônia, 4, 2015, Belém, PA. Anais... Simpósio de Estudos e pesquisas em Ciências Ambientais na Amazônia p. 1-10. On-line. ISSN 2316-7637. Disponível em: < http://www4.uepa.br/paginas/pcambientais/simposio/anais_artigos_vol_1_simposio_2015.pdf >. Acesso em: 01 nov. 2016.

MENGATTO JUNIOR, E. A. M.; SILVA. J. dos S. V.; OLIVEIRA, R. C. Ferramenta técnica como suporte à gestão do território. In: Simpósio de Geotecnologias no Pantanal, 6, 2016, Cuiabá. Anais... São José dos Campos: INPE, 2016. CD-ROM. ISBN 978-85-17-00085-0.

PARÁ. Zoneamento Ecológico-Econômico das Zonas Leste e Calha Norte do Estado do Pará /Editores Técnicos: Carmen Roseli Caldas Menezes, Marcilio de Abreu Monteiro e Igor Maurício Freitas Galvão. Belém, PA: Núcleo de Gerenciamento do Programa Pará Rural, 2010. v1. 309p. :il.; 22x30 cm. 